\title{
Optimization of shrimp shell waste deacetylation for chitosan production
}

\author{
Flornica Alca Ahing*, Newati Wid
}

Faculty of Science and Natural Resources, Universiti Malaysia Sabah, Jalan UMS, 88400, Kota Kinabalu, Sabah, Malaysia

\section{ARTICLE INF O}

\section{Article history:}

Received 12 August 2016

Received in revised form

5 October 2016

Accepted 11 October 2016

\section{Keywords:}

Chitosan

Shrimp shell waste

Repeat deacetylation

Chitosan solubility

Degree of deacetylation

\section{Introduction}

Shrimp is considered as one of the most important fisheries product in Sabah, Malaysia which mostly exported in frozen condition after separation of the head and shell. Shrimp industries in Sabah generally produces large scale of shrimp bio-waste during the processing which have only low economic value thus being dispose on landfill constantly. However, this bio-waste which includes head and shell can produce value-added products such as chitosan which is derived from chitin that generally found in marine invertebrates, insect, and fungi and chitosan is easily formed into various semi-solid and solid structures under mild conditions (Szymanska and Winnicka, 2015). According to Nouri et al. (2016) and Ning and Xi (2015), the shrimp waste contains protein $(30-40 \%)$, calcium carbonate $(30$ $50 \%$ ) and chitin (20-30\%).

Chitosan which is a modified natural carbohydrate is a polycationic copolymer which consisting of glucosamine and $\mathrm{N}$-acetylglucosamine units possesses a free amino group $\left(\mathrm{NH}_{2}\right)$ which is reactive in many chemical reaction. The difference of group in the position $\mathrm{C}-2$ of chitosan which is $\mathrm{NH}_{2}$ instead of hydroxyl group $(\mathrm{OH})$ for cellulose makes chitosan can easily form positive ionic charge which

\footnotetext{
* Corresponding Author.

Email Address: ikalca88@gmail.com (F. A. Ahing)

https://doi.org/10.21833/ijaas.2016.10.006

2313-626X/C) 2016 The Authors. Published by IASE.

This is an open access article under the CC BY-NC-ND license

(http://creativecommons.org/licenses/by-nc-nd/4.0/)
}

can increases the ability to chemically bind with negatively charged compounds such as fats, lipids, cholesterol, metal ions, proteins, and macromolecules (Hossain and Iqbal, 2014).

Due to its excellent properties, this has made chitosan attained increasing commercial interest worldwide such as agriculture, biochemistry, pharmaceuticals, biotechnology, biomedical, cosmetics, food, and paper industry (Rinaudo, 2006). Chitosan has been explored for its uses in agricultural and horticultural which primarily for plant defense and enhance production yield by promoting plant growth as well as in pharmaceutical and biomedical which includes prolonged or controlled release drug delivery systems, wound dressing, blood anticoagulants, cartilage and bone tissue engineering scaffolds, and also space filling implants.

Among several properties which make chitosan available in industries were the degree of deacetylation and solubility. In most commercial industry, it needs a soluble chitosan so that it can make it available in many chitosan based material processes.

The process of chitosan extraction from chitin usually is by using conventional method which comprises deproteination by alkaline solution, demineralization by acid solution and lastly deacetylation by concentrated alkaline solution. In this conventional method, generally the deacetylation process is done once at certain temperature to obtained high acetylated chitin. However, to achieve high degree of deacetylation, 
deacetylation process can be repeated twice at different temperature because heating treatment may increase the reaction. Therefore, the objectives of this study are to investigate the optimum condition during of soaking frequency and temperature to produce high degree of deacetylated of chitosan and to determine the characteristics of chitosan produced.

\section{Materials and methods}

\subsection{Sample collection and preparation}

The raw shrimp shell waste was collected from Kian Huat Seagull Sdn Bhd, Putatan which nearby Kota Kinabalu city and it is one of the factories which produced large quantities of shrimp shell waste in Sabah. The sample was collected is fresh conditions where it is collected during the peeled of process of the shrimp shell. The samples was washed with tap water to remove any insoluble material on the shell then dried under the sun for 8 hours. The sample was stored in a closed container prior to use.

\subsection{Deproteination}

This process was performed at laboratory scale where a total of $30 \mathrm{~g}$ samples of raw shrimp shell waste were added with $2.0 \mathrm{M} \mathrm{NaOH}$ in the ratio $1: 16$ $(\mathrm{w} / \mathrm{v})$ then left for 48 hours at room temperature, $\sim 25^{\circ} \mathrm{C}$ (Kumari and Rath, 2014). After that, the solution was filtered and the samples were washed with distilled water until neutral $\mathrm{pH}$ was achieved (pH6.5-8.0). Water from the samples was removed before performing the demineralization process by filtration method.

\subsection{Demineralization}

The demineralization process were carried out by added with $1.0 \mathrm{M} \mathrm{HCl}$ in the ratio $1: 16(\mathrm{w} / \mathrm{v})$ and allowed to stand for 24 hours (Puvvada et al., 2012) at room temperature $\left(\sim 25^{\circ} \mathrm{C}\right)$. The samples were then dried under the sun for 6-8 hours and the dried sample is now known as chitin.

\section{Chitosan production}

\subsection{Deacetylation (DA)}

\subsubsection{Soaking frequency}

The deacetylation process was done with a modification by Miya et al. (1985) and Wan et al. (2003) by soaking the dried chitin prepared with $48 \% \mathrm{NaOH}$ for 48 hours at room temperature $\left(\sim 25^{\circ} \mathrm{C}\right)$. After soaking, the product is known as chitosan (Kumari and Rath, 2014). The chitosan was washed with tap water until neutral (pH6.5-8.0) and dried as described in demineralization process. The procedure was repeated to get different frequency of soaking process (deacetylation). Deacetylation process was carried out once (C1) and twice (C2) representing soaking once and soaking twice, respectively. The chitosan obtained from each treatment (C1 and C2) was further investigated for its properties.

\subsubsection{Temperature}

Treatment of deacetylation twice (C2) was further investigated at different temperature (60 and $80^{\circ} \mathrm{C}$ ) to determine the optimum temperature in obtaining chitosan with high degree of deacetylation.

\section{Characterization of prepared chitosan}

The characterization of the extracted chitosan was performed in term of the solubility and degree of deacetylation (DDA) for all chitosan produced from each deacetylation treatments (C1 and C2).

\subsection{Solubility in acid solution}

$1.0 \mathrm{~g}$ of chitosan obtained from the deacetylation process was dissolved in $100 \mathrm{~mL}$ of $1 \%$ acetic acid solution and stirred by magnetic stirrer until a homogeneous solution was obtained. The chitosan acidic solution was then filtered using a vacuum pump. The procedure was repeated three times. The percentage of the solubility was calculated as follows: (Puvvada et al., 2012).

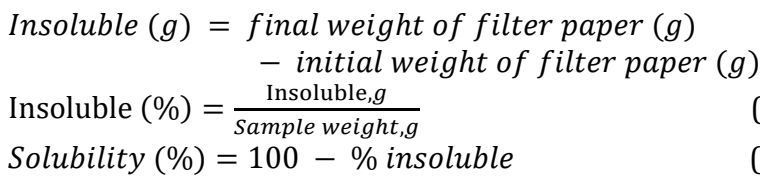

\subsection{Degree of Deacetylation}

The samples of chitosan produced were characterized using Fourier Transform Infrared (FTIR) spectrophotometer in the range of 400 to $4000 \mathrm{~cm}^{-1}$ and repeated for three replicates. The DDA of the sample were determined according to the method used by Brugnerotto et al. (2001). The A1320 was the peak area of the band $1320 \mathrm{~cm}^{-1}$, the $A_{1420}$ was the peak area of $1420 \mathrm{~cm}^{-1}$ which representing the peak for amide group and amine group, respectively. The DDA calculation was carried out as follows:

$$
\begin{aligned}
& \% \mathrm{DA}=\frac{\left(A_{1320} / A_{1420}\right)-0.3822}{0.03133} \\
& \% \mathrm{DDA}=100-\% \mathrm{DA}
\end{aligned}
$$

where,

$$
\begin{aligned}
& D D A=\text { degree of deacetylation (\%) } \\
& D A=\text { degree of acetylation }(\%)
\end{aligned}
$$

\section{Results and discussion}

\subsection{The produced chitosan}


The physical appearance of the $\mathrm{C} 1$ was slightly yellowish white, while for C2 it was white in color (Fig. 1). It was also odorless and in a form of crystalline flakes. The characteristic of the chitosan produced from this study was similar to the chitosan

(a)

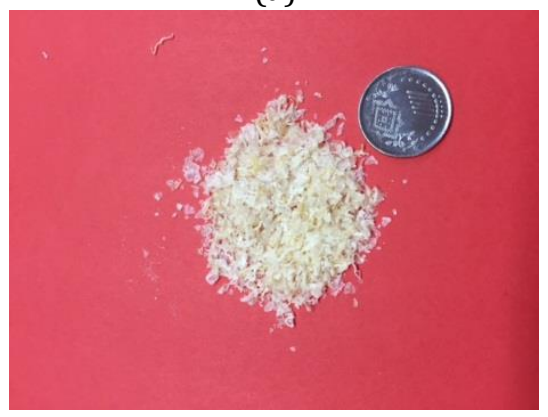

Fig. 1: Chitosan produced for C1 (a) and C2 (b) obtained from previous studies which was slightly brownish to white and yellowish white and this indicates a good quality of chitosan was produced (Naznin, 2005; Nouri et al., 2016).

(b)

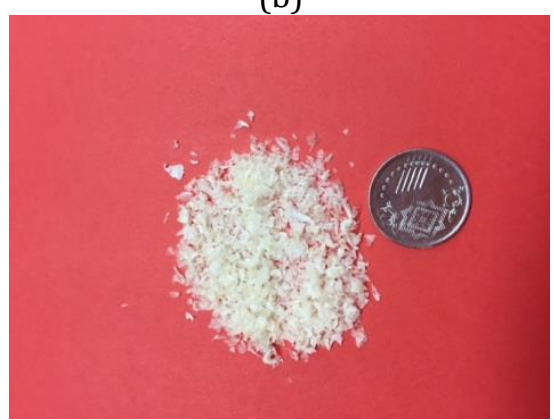

\subsection{Solubility}

Among several characteristics, solubility of chitosan is one of the most important parameter for quality of chitosan, where higher solubility means better quality of chitosan. Chitosan is a compound which is very difficult to dissolve in water, alkaline solutions or most common organic solvents but it is soluble to some extent in dilute aqueous acid solutions (El-hefian et al., 2009). There are several main factors which may affecting the solubility of chitosan such as temperature and time treatment of deacetylation, concentration of alkaline solution, ratio of chitin to alkali solution and soaking frequency in $\mathrm{NaOH}$ solution for the deacetylation process. Fig. 1 shows the solubility of chitosan obtained from the effect of soaking frequency where for the deacetylation process once (C1) and twice (C2) which was conducted at room temperature $\left(\sim 25^{\circ} \mathrm{C}\right)$. The solubility for $\mathrm{C} 1$ and $\mathrm{C} 2$ were $97.78 \%$ $( \pm 0.2450)$ and $98.32( \pm 0.0360)$, respectively. As seen it Fig. 1, the effect of soaking frequency increased the solubility of chitosan, where soaking twice in $48 \%$ $\mathrm{NaOH}$ at room temperature for deacetylation process has higher solubility of $98.32 \%( \pm 0.036)$ compared to one time soaking with $97.78 \%$. It shows that by repeating deacetylation twice, it can enhance the solubility of chitosan produced thus producing a better quality of chitosan (Figs. 2 and 3).

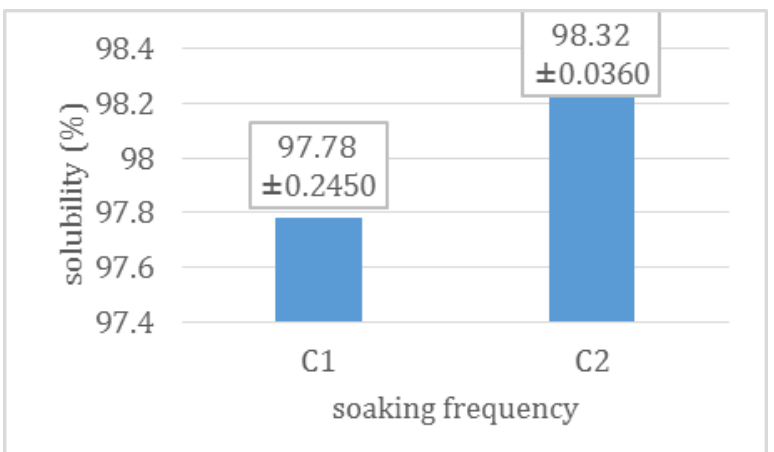

Fig. 2: Percentage of solubility of chitosan for C1 and C2 at room temperature $\left(\sim 25^{\circ} \mathrm{C}\right)$

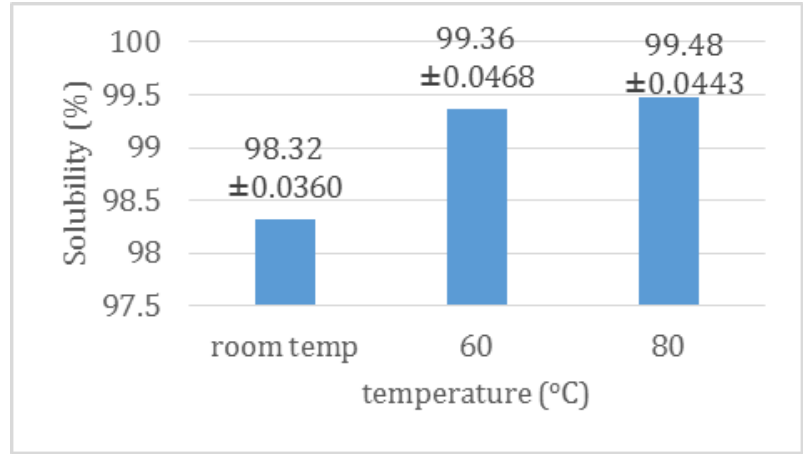

Fig. 3: Solubility of chitosan for deacetylation twice at different temperature

Meanwhile, when C2 treatment was performed under different temperature, the solubility of chitosan increased with average 99.36\% $( \pm 0.0468)$ for temperature at $60^{\circ} \mathrm{C}$ whereas at $80^{\circ} \mathrm{C}$ the solubility can be achieved up to $99.48 \%( \pm 0.0443)$, with the support of temperature (Fig. 2). Previous study which was done by Patria (2013) reported that the solubility achieved was $17.43 \%$ to $95.29 \%$ with average of $57.52 \%$ at different deacetylation temperature $60,70,80$ and $90^{\circ} \mathrm{C}$ whereas another study also showed the solubility obtained was ranged from $48.30 \%$ to $97.65 \%$ by performing deacetylation once at temperature $65^{\circ} \mathrm{C}$ but using different concentration of $\mathrm{NaOH}(30,40,50,60 \%)$ (Hossain and Iqbal, 2014). There is no literature reported on the solubility of deacetylated twice of chitosan yet, however by comparing the solubility of this study to previous studies which has been done, is shows that by repeating the deacetylation process twice, it increases the amount of amino groups $\left(\mathrm{NH}_{2}\right)$ in the chitosan polymer chain thus increasing the solubility of chitosan. When the deacetylation process was carried out at different temperature, higher percentage of solubility was found at higher temperature, i.e. $80^{\circ} \mathrm{C}$, with $99.48 \%$ solubility.

An increases in solubility is proportionally to the degree of deacetylation is due to the acetyl groups where in chitin deacetylation process, it will be removed and leaving only amine group. Chitosan will get protonated in the aqueous acid solution which leads to its solubility is due the presence of amino 
group in its molecular structure (El-hefian et al., 2009) Amine group contains hydrogen ions which makes chitosan can easily interact with water through hydrogen bonding in addition with the presence of carboxyl group in acetic acid would facilitate the dissolution of chitosan due to the hydrogen interaction between the carboxyl group and the amine group of chitosan as shown in Eq. 5 (Patria, 2013). Additionally, the solubility test of chitosan is important because it is a routine stage in most of the processing of chitosan for its application especially in pharmaceutical technology of chitosan based formulations.

$$
-\mathrm{NH}_{2}+\mathrm{H}_{2} \mathrm{O} \rightarrow-\mathrm{NH}_{2} \mathrm{NH}_{3}^{+}+\mathrm{OH}^{-}
$$

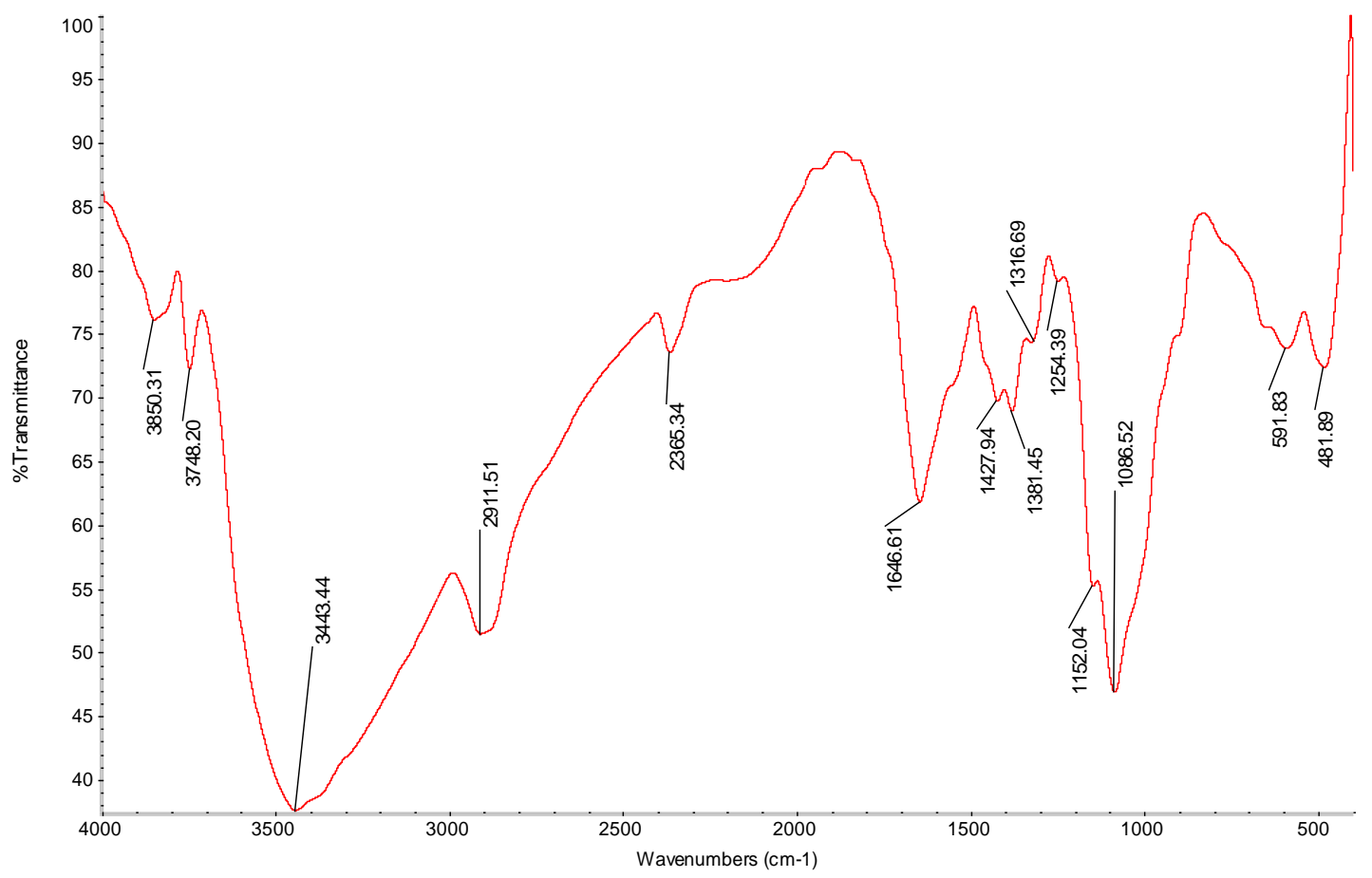

Fig. 4: FTIR spectra form chitosan obtained from deacetylated twice at $80^{\circ} \mathrm{C}$

Based on these spectra, the major absorption band is observed at 3443 which indicates the stretching vibration of $\mathrm{OH}$ and $\mathrm{NH}$ groups. Between 1250 and $1080 \mathrm{~cm}^{-1}$ which represents the free amino group $\left(-\mathrm{NH}_{2}\right)$ at $\mathrm{C} 2$ position of glucosamine indicates a major group that present in chitosan. FTIR spectra obtained for the chitosan produced showed the absorption bands for the free amino group between 1086 and $1254 \mathrm{~cm}^{-1}$ and also some bands which is also reported by Zhou et al. (2008) where same strong characteristic amino peaks of chitosan at 3420,1655 , and $1325 \mathrm{~cm}^{-1}$. Some of the bands were also observed by Puvvada et al. (2002), 2911 (symmetric $\mathrm{CH}_{3}$ and asymmetric $\mathrm{CH}_{2}$ stretching), 1584 ( $-\mathrm{C}=0$ secondary amide), and 1421 ( $-\mathrm{CN}$ secondary amide). The intensity of the absorption band around 1595 for very short due to highly degree of deacetylation. Nevertheless, based on Coates (2000), it is not sufficient to characterize the functional group for the different classes of carbonyl compound overlap and the carbonyl frequency alone. The degree of deacetylation was calculated

\subsection{Degree of Deacetylation (DDA)}

Degree of deacetylation (DDA) of chitosan is the most important parameter in this study because DDA can be used to determine the quality of chitosan produced where it affects the chemical, physical and biological properties of the chitosan such as adsorption, covalent linking and encapsulation (Puvvada et al., 2012). The DDA value was determined by using FTIR as was explained in the experimental part using the ratio of the bands at 1320 and $1420 \mathrm{~cm}^{-1}$. Fig. 3 shows the FTIR spectra for chitosan which produced in this study (Fig. 4). 
the DDA value of chitosan obtained was up to $90 \%$ by performing the deacetylation in an autoclave, while Al Sagheer et al. (2009) reported that the chitosan DDA obtained from shrimp shell waste in Arabian Gulf ranged from $88-94 \%$ by using traditional method. Nouri et al. (2016) also obtained DDA value ranged from 71.02-82.20\% for deacetylation using traditional method, while 79.01$88.60 \%$ for using microwave method. Besides, Alishahi et al. (2011) also performed deacetylation by using microwave and obtained chitosan with DDA value ranged from 87.5 - 93\%. By using higher concentration of alkaline solution which was $50 \%$ $\mathrm{NaOH}$ for deacetylation process, DDA can be increased to $89.79 \%$ (Puvvada et al., 2012). The result shows in Fig. 4 indicates that the best condition to produce a high DDA value is by repeating the deacetylation process twice, where a higher DDA value can be increased to $88.57 \%$ compared to deacetylation once with $75.24 \%$. However, with the aid of heating treatment during deacetylaion twice, it enhanced the DDA value and the result is showed in Fig. 5.

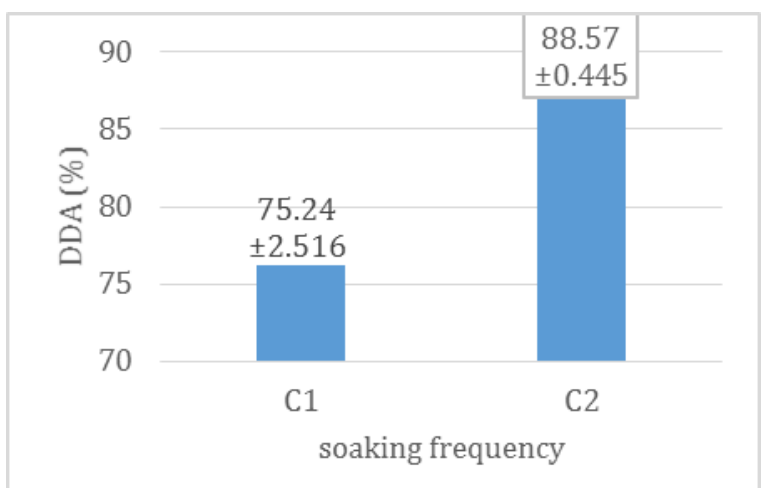

Fig. 5: Effect of soaking frequency at room temperature on DDA value

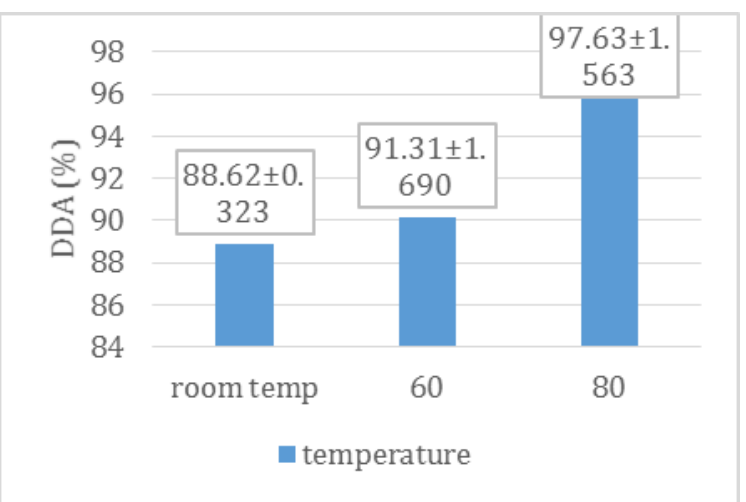

Fig. 6: DDA value for chitosan samples after deacetylated twice at different temperature

The degree of deacetylation (DDA) obtained from this study when deacetylation repeated twice was ranged from 88.62 to $97.63 \%$, where the highest value of DDA was obtained by deacetylation twice with the aid of heat treatment at $80^{\circ} \mathrm{C}$. These results showed that the heating treatment on the deacetylation process affects significantly the deacetylation of chitin to produce better quality of chitosan with higher DDA value. Previous study done by Wan et al. (2003) reported that the chitosan obtained highest DDA value $95.1 \%$ when performing deacetylation twice but the process was performed in a reactor at $100^{\circ} \mathrm{C}$ using $50 \% \mathrm{NaOH}$ for 1 hour treatment. Another study which also conducted deacetylation twice is done by Zhou et al. (2008) and managed to produce chitosan with DDA value $90.3 \%$ by performing with $50 \% \mathrm{NaOH}$ at $100^{\circ} \mathrm{C}$ for 30 minutes. This explains that the DDA values can be different due to series of parameters used or conditions during the deacetylation process. However, based on these several previous studies with this study, it shows that a higher DDA value can be obtained by repeating deacetylation process twice but with the aid of heat at $80^{\circ} \mathrm{C}$ and longer time treatment. The DDA value can be achieved up to $97.63 \%$ compared to the other methods performed in the previous studies.

\section{Conclusions}

Based on the results obtained from this study, the traditional method of extracting chitosan can produces chitosan with solubility up to $97.78 \%$ and DDA value $75.24 \%$. When the deacetylation process repeated twice with the aid of heating treatment, a better quality of chitosan can be obtained with the solubility of chitosan can be achieved up to 99.48 at temperature $80^{\circ} \mathrm{C}$, while DDA value obtained was high up to $97.63 \%$. Soaking frequency twice (C2) enhanced chitosan solubility but no significant effect observed when C2 performed at different temperature. Meanwhile, the DDA value increased for $\mathrm{C} 2$ and a higher DDA value was achieved at $80^{\circ} \mathrm{C}$ when performed twice. From these results, it can be concluded that by repeating the deacetylation twice and also with the support of heating treatment, it can be used to produce a better quality of chitosan with higher solubility and DDA value.

\section{Acknowledgment}

The authors would like to acknowledge the Enviro Clean Energy (Sdn. Bhd) and Malaysian Nuclear Agency for the financial and technical supports (GL0129), as well as the lab assistants at the Faculty of Science and Natural Resources and Biology Tropical and Conservation Institute, Universiti Malaysia Sabah, for their assistance.

\section{References}

Abdou ES, Nagy KS and Elsabee MZ (2008). Extraction and characterization of chitin and chitosan from local sources. Bioresource Technology, 99(5): 1359-1367.

Al Sagheer FA, Al-Sughayer MA, Muslim S and Elsabee MZ (2009). Extraction and characterization of chitin and chitosan from marine sources in Arabian Gulf. Carbohydrate Polymers, 77(2): 410-419. 
Alishahi A, Mirvaghefi A, Tehrani MR, Farahmand H, Shojaosadati SA, Dorkoosh FA and Elsabee MZ (2011). Enhancement and characterization of chitosan extraction from the wastes of shrimp packaging plants. Journal of Polymers and the Environment, 19(3): 776-783.

Brugnerotto J, Lizardi J, Goycoolea FM, ArgüellesMonal W, Desbrieres J and Rinaudo M (2001). An infrared investigation in relation with chitin and chitosan characterization. Polymer, 42(8): 35693580 .

Coates J (2000). Interpretation of infrared spectra, a practical approach. In: Meyers RA (Eds.), Encyclopedia of Analytical Chemistry. John Wiley \& Sons Ltd, Chichester: 10815-10837. https://doi.org/10.1002/9780470027318.a5606

El-hefian EA, Yahaya AH and Misran M (2009). Characterisation of chitosan solubilised in aqueous formic and acetic acids. Maejo International Journal of Science and Technology, 3(3): 415-425.

Hossain MS and Iqbal A (2014). Production and characterization of chitosan from shrimp waste. Journal of the Bangladesh Agricultural University, 12(1): 153-160.

Kasaai MR (2008). A review of several reported procedures to determine the degree of $\mathrm{N}$ acetylation for chitin and chitosan using infrared spectroscopy. Carbohydrate Polymers, 71(4): 497-508.

Kumari S and Rath PK (2014). Extraction and characterization of chitin and chitosan from (Labeo rohit) fish scales. Procedia Materials Science, 6: 482-489.

Miya M, Iwamoto R, Ohta K and Mima S (1985). Nacetylation of chitosan films. Kobunshi Ronbunshu, 42(3): 181-189.
Nessa F, Masum SM, Asaduzzaman M, Roy SK, Hossain MM and Jahan MS (2010). A process for the preparation of chitin and chitosan from prawn shell waste. Bangladesh Journal of Scientific and Industrial Research, 45(4): 323330.

Ning Y and Xi C (2015). Sustainability: Don't waste seafood waste. Nature 524(7564):155-157.

Nouri M, Khodaiyan F, Razavi SH and Mousavi M (2016). Improvement of chitosan production from Persian Gulf shrimp waste by response surface methodology. Food Hydrocolloids, 59: 5058.

Patria A (2013). Production and characterization of Chitosan from shrimp shells waste. AACL Bioflux, 6(4): 339-344.

Puvvada YS, Vankayalapati S and Sukhavasi S (2012). Extraction of chitin from chitosan from exoskeleton of shrimp for application in the pharmaceutical industry. International Current Pharmaceutical Journal, 1(9): 258-263.

Rinaudo M (2006). Chitin and chitosan: properties and applications. Progress in polymer science, 31(7): 603-632.

Szymanska E and Winnicka K (2015). Stability of chitosan-a challenge for pharmaceutical and biomedical applications. Marine Drugs, 13(4): 1819-1846.

Wan Y, Creber KA, Peppley B and Bui VT (2003). Ionic conductivity of chitosan membranes. Polymer, 44(4): 1057-1065.

Zhou HY, Chen XG, Kong M, Liu CS, Cha DS and Kennedy JF (2008). Effect of molecular weight and degree of chitosan deacetylation on the preparation and characteristics of chitosan thermosensitive hydrogel as a delivery system. Carbohydrate Polymers, 73(2): 265-273. 